\title{
Antioxidant and Anti-Inflammatory Activities of Phytochemicals from Ruellia tuberosa
}

\author{
Trinh Nhat Thi Pham $\mathbb{D}^{1},{ }^{1}$ Tuan Trong Nguyen ${ }^{\left(\mathbb{D},{ }^{2}\right.}$ Thuy Le Thi Nguyen ${ }^{\mathbb{D}},{ }^{3}$ \\ An Minh Nguyen Tran $\mathbb{D}^{4},{ }^{4}$ Tuan Ngoc Nguyen $\mathbb{D}^{4},{ }^{4}$ Danh Thanh Tong $\mathbb{D},{ }^{5,6}$ \\ and Dung Tien Le ${ }^{7,8}$ \\ ${ }^{1}$ Department of Biochemistry, Tiengiang University, My Tho, Tiengiang, Vietnam \\ ${ }^{2}$ Department of Chemistry, Can Tho University, Can Tho, Vietnam \\ ${ }^{3}$ Department of Food Technology, Ho Chi Minh City Open University, Ho Chi Minh, Vietnam \\ ${ }^{4}$ Industrial University of Ho Chi Minh City, HoChiMinh, Vietnam \\ ${ }^{5}$ Department of Organic Chemistry, Ho Chi Minh City University of Technology (HCMUT), Ho Chi Minh, Vietnam \\ ${ }^{6}$ Vietnam National University Ho Chi Minh City, Linh Trung Ward, Thu Duc District, Ho Chi Minh, Vietnam \\ ${ }^{7}$ Department of Pharmaceutical Biochemistry, Institute of Applied Materials Science, \\ Vietnam Academy of Science and Technology, Ho Chi Minh, Vietnam \\ ${ }^{8}$ Graduate University of Science and Technology, Vietnam Academy of Science and Technology, Ha Noi, Vietnam
}

Correspondence should be addressed to Dung Tien Le; inpcdung@yahoo.com

Received 28 November 2021; Revised 23 December 2021; Accepted 7 January 2022; Published 25 January 2022

Academic Editor: Andrea Mastinu

Copyright (C) 2022 Trinh Nhat Thi Pham et al. This is an open access article distributed under the Creative Commons Attribution License, which permits unrestricted use, distribution, and reproduction in any medium, provided the original work is properly cited.

\begin{abstract}
In Vietnam, the aerial parts of Ruellia tuberosa L. are used to treat stress oxidation and inflammatory symptoms in diabetes mellitus. The present study was designed to determine the antioxidant and inflammatory inhibition activities of Ruellia tuberosa L. extract (RTE) and those of the isolated compounds by column chromatography. The crude ethanol extract and ethyl acetate fraction exhibited potent antioxidant activity in the 2,2-diphenyl-1-picryl-hydrazyl-hydrate (DPPH) and 2,2-azinobis-(3-ethylbenzothiazoline-6-sulfonate) (ABTS) assays with an $\mathrm{IC}_{50}$ of 25.18 and 14.71 (DPPH test) and $18.22 \mathrm{and} 15.27 \mu \mathrm{g} / \mathrm{ml}$ (ABTS test), respectively. The RTE contained high concentrations of polyphenols $(308.21 \mathrm{mg} \mathrm{GAE} / \mathrm{g})$ and moderate concentrations of flavonoids $(97.80 \mathrm{mg} \mathrm{QE} / \mathrm{g})$. In the anti-inflammatory screening assay, the crude ethanol extract, ethyl acetate, and methanol fractions suppressed the release of IL- 6 and nitric oxide production, but the production of IL-10 was not enhanced in LPS-induced RAW 264.7 cells. Three potential anti-inflammatory compounds as hispidulin (6), physalin E (7), and physalin D (8) along with five other compounds named myricitrin (1), afzelin (2), apigenin (3), taraxerol (4), and lupeol (5) were isolated and identified from the ethyl acetate fraction. Physalin D (8) exhibited a strong, dose-dependent anti-inflammatory activity by inhibiting the production of IL- 6 proinflammatory cytokines; however, the IL-10 expression was independent of its concentration in macrophages at noncytotoxic concentrations ranging from 5 to $40 \mu \mathrm{g} / \mathrm{mL}$. Based on the data obtained, compounds 6-8 sourced from Ruellia tuberosa $\mathrm{L}$ are potentially bioactive compounds for the treatment of inflammation symptoms in type 2 diabetes mellitus.
\end{abstract}

\section{Introduction}

Diabetes mellitus is a chronic disease that is related to high plasma glucose because of a shortage of insulin production, insulin action, or both. The goal of type 2 diabetes treatment is to regulate blood glucose levels at normal or near-normal levels [1]. Recent studies have revealed a relationship between diabetes mellitus and secondary complications manifesting from chronic inflammation in people with diabetes. Therefore, in addition to lowering plasma glucose levels, hypoglycemic agents reduce inflammatory symptoms, thus leading to better outcomes [2]. Inflammation is considered an important etiological factor in the development of both types 1 and 2 diabetes mellitus [3]. Moreover, high blood glucose levels promote the autooxidation of glucose to form free radicals, which cause diabetes [4]. An excessive 
increase in reactive oxygen species or reactive nitrogen species accompanied by a decrease in antioxidants induces oxidative stress, which can lead to endothelial dysfunction, insulin resistance, and alterations in the number of reactive oxygen species and function of pancreatic beta cells [5]. Antioxidants can slow or inhibit cell damage due to their free radical scavenging activity [6]. Therefore, phytochemicals with hypoglycemic, anti-inflammatory, and antioxidant activities are suited for the treatment of diabetes.

Traditional medicines, which utilize medicinal plants, are used by most of the global populace to treat various diseases. Ruellia tuberosa L., a Vietnamese medicinal plant, has been used for the treatment of diabetes mellitus as an anti-inflammatory and diuretic agent [7]. The aerial part of this plant exhibited significant hypoglycemic effects in alloxan-induced diabetic rats and rabbits $[8,9]$, and the leaf extract is a good inhibitor of the lipoxygenase enzyme [10]. Five flavonoids, including cirsimaritin, cirsimarin, cirsiliol $4^{\prime}$-glucoside, sorbifolin, and pedalitin, as well as betulin, vanillic acid, and indole-3-carboxaldehyde, were isolated from the ethyl acetate extract of $R$. tuberosa L. [11]. Seven compounds, which are apigenin and luteolin derivatives, were also isolated from $R$. tuberosa L. $[12,13]$. As part of our continuing research on the biological activities and phytochemicals of medicinal plants [14-16], this study isolated potential anti-inflammatory compounds from $R$. tuberosa extract and evaluated their antioxidant and inflammatory inhibition activities.

\section{Materials and Methods}

2.1. Chemicals. 2,2-Diphenyl-1-picryl-hydrazyl-hydrate (DPPH, Cat. No. 257621), 2,2-azinobis-(3-ethylbenzo thiazoline-6-sulfonate) (ABTS, Cat. No. 10102946001), potassium persulfate (Cat. No. 216224), trifluoroacetic acid (Cat. No. 302031), ascorbic acid (Cat. No. 57803), gallic acid (Cat. No. G7384), quercetin (Cat. No. PHL89262), Trolox (Cat. No. 238813), and the Folin-Ciocalteu reagent (Cat. No. 47641) were purchased from Sigma-Aldrich (St. Louis, MO, USA). Solvents including hexane (Cat. No. 1043742500), chloroform (Cat. No. 1024322500), ethyl acetate (Cat. No. 1007892500), ethanol (Cat. No. 1009744000), and methanol (Cat. No. 1060182500) were obtained from Merck (Darmstadt, Germany). Standard solutions were prepared using deionized water. Dulbecco's modified Eagle's medium (Cat. No. 11995040), 0.25\% trypsin-EDTA (Cat. No. 25200072), penicillin-streptomycin (Cat. No. 15070063), sodium pyruvate (Cat. No. 11360070), and fetal bovine serum (Cat. No. A3840001) were purchased from Thermo Scientific (Waltham, MA, USA). Enzyme-linked immunosorbent assay reagents for IL-6 (Cat. No. 88-7064-88) and IL-10 (Cat. No. 88-7105-77) cytokine were obtained from eBioscience (San Diego, CA, USA). Lipopolysaccharide (Cat. No. L7770), dimethyl sulfoxide (Cat. No. 276855), $\mathrm{Na}_{2} \mathrm{CO}_{3}$ (Cat. No. 222321), $\mathrm{AlCl}_{3}$ (Cat. No. 563919), and phosphate buffered saline pH 7.4 (Cat. No. 806552) were purchased from SigmaAldrich Co. (Mumbai, India).
2.2. Plant Material. The aerial part of Ruellia tuberosa L. was collected in Tien Giang Province, Vietnam, in July 2017. A voucher specimen (D072017) was preserved at the Department of Pharmaceutical Biochemistry, Institute of Applied Materials Science (VAST, Ho Chi Minh City, Vietnam) by Dr. Luu Hong Truong.

2.3. Instruments. Melting points were determined using an IA9100 Digital Melting Point Apparatus (Cole-Parmer, United States). NMR spectra were recorded on a Bruker AM500 FTNMR spectrometer (Bruker, Karlsruhe, Germany) with an internal standard (TMS, Institute of Chemistry, VAST, Hanoi, Vietnam). Thin layer chromatography was performed on precoated silica gel 60 F254 (1.05554.0001, Merck, Darmstadt, Germany) and RP-18 F254S plates (1.15685.0001, Merck, Darmstadt, Germany). The zones on the TLC plates were detected by UV light or a solution of $10 \%(\mathrm{v} / \mathrm{v}) \mathrm{H}_{2} \mathrm{SO}_{4}$ in $\mathrm{EtOH}$ solution. Column chromatography was performed on silica gel (240-430 mesh, Merck, Darmstadt, Germany), octadecylsilane (70-230 mesh, Merck, Darmstadt, Germany), and Sephadex LH-20 (GE Healthcare Bio-Sciences AB, Uppsala, Sweden).

2.4. Extraction. The dried sample powder of Ruellia tuberosa L. $(5.0 \mathrm{~kg})$ was extracted with $96 \%$ ethanol at $30 \mathrm{C}$ four times $(4 \times 30 \mathrm{~L})$ and then filtered. The solvent was removed from the filtrate using a rotary evaporator, and a crude extract (RTE, $350 \mathrm{~g}$ ) was obtained. The extract was successively partitioned into $n$-hexane (RTH), ethyl acetate (RTEA), and methanol (RTM) fractions using a flash silica gel column. The dried fractions $(10 \mathrm{~g})$ were stored in a refrigerator at $4 \mathrm{C}$ to determine the antioxidant properties (total flavonoids, polyphenols, DPPH, and ABTS assays) and anti-inflammatory activities.

2.5. Isolation. The remaining ethyl acetate fraction was chromatographed on a silica gel column and eluted with a mixture of hexane and ethyl acetate $(0: 1-1: 0, \mathrm{v} / \mathrm{v})$ to obtain six subfractions (E1-6). Fraction E1 was rechromatographed on a silica gel column using a mixture of hexane and ethyl acetate (from $30: 1$ to $10: 1, \mathrm{v} / \mathrm{v}$ ) as the eluent and this afforded five fractions (E1.1-5). Fraction E1.1 was loaded on a silica gel column, eluted with chloroform : methanol (95:5 to $90: 10, \mathrm{v} / \mathrm{v}$ ), purified via an ODS column, and eluted with methanol: water $(3: 1, \mathrm{v} / \mathrm{v})$. This resulted in $7(22 \mathrm{mg})$ and 8 $(15.8 \mathrm{mg})$. Fraction E1.4 was chromatographed on a silica gel column and eluted with chloroform : methanol (70:1 to 10 : 1, v/v), and this afforded five subfractions (E1.4.1-5). Fraction E1.4.2 was loaded on a silica gel column and eluted with chloroform: methanol $(30: 1, \mathrm{v} / \mathrm{v})$. This afforded 4 (11.3 $\mathrm{mg})$ and 6 (8.4 mg). Fraction E1.4.3 was purified using Sephadex LH20 (chloroform : methanol = $1: 1, \mathrm{v} / \mathrm{v}$ ) and then further chromatographed on an ODS column and eluted with methanol: water $(1: 1.5, \mathrm{v} / \mathrm{v})$, and this yielded 5 (10.5 mg). 
Fraction E2 was applied to a flash silica gel column and eluted with hexane: acetone $(10: 1$ to $3: 1, \mathrm{v} / \mathrm{v})$ to yield five fractions (E2.1-5). Subfraction E2.3 was subsequently loaded onto a silica gel column and eluted with a gradient of chloroform-isopropanol (5-30\%, v/v), and this yielded compound 3 (9.8 mg). Fraction E2.5 was further chromatographed on an ODS column with a mixture of methanol and water $(1: 3$ to $1: 1, \mathrm{v} / \mathrm{v})$ and afforded three fractions (E2.5.1-3). Subfraction E2.5.2 was loaded on a Sephadex LH 20 column, eluted with $\mathrm{MeOH}$, and then purified on an ODS column using acetonitrile-water $(1: 2.5, \mathrm{v} / \mathrm{v})$ and yielded compounds 1 (22.1 $\mathrm{mg}$ ) and $2(14.3 \mathrm{mg})$.

2.6. Quantification of Total Polyphenols. The polyphenol content was measured using the Folin-Ciocalteu method [17]. Briefly, a known concentration $(50 \mu \mathrm{g} / \mathrm{mL})$ of the extracts $(1 \mathrm{~mL})$ was mixed with Folin-Ciocalteu reagent $(1 \mathrm{~mL})$ for $5 \mathrm{~min}$. A saturated $\mathrm{Na}_{2} \mathrm{CO}_{3}$ solution $(2 \mathrm{~mL})$ was subsequently added to the mixture, and the new mixture was placed in the dark for $90 \mathrm{~min}$ at room temperature. The absorbance was measured using a UV spectrophotometer (Shimadzu, UV-1800) at $760 \mathrm{~nm}$. The polyphenolic content was expressed as $\mathrm{mg}$ of gallic acid equivalents per gram of dry extract (mg GAE/g).

2.7. Determination of Total Flavonoids. The aluminum chloride colorimetric method was used to determine the total flavonoid content of the sample [18]. Quercetin was used to establish a standard calibration curve for the experiment. A solution of quercetin was prepared by dissolving quercetin $(5.0 \mathrm{mg}$ quercetin in $1.0 \mathrm{~mL}$ methanol) and then diluted with methanol to obtain known concentrations. Quercetin and the extract solution $(0.6 \mathrm{~mL})$ were mixed with $2 \%$ aluminum chloride $(0.6 \mathrm{~mL})$ and left to stand for $60 \mathrm{~min}$ at room temperature. The absorbance of the mixtures was measured against a blank at $420 \mathrm{~nm}$ using a UV-Vis spectrophotometer. The total flavonoids content was expressed as mg quercetin equivalent $(\mathrm{QE}) / \mathrm{g}$ of dried extract (mg QE/ g).

2.8. DPPH Radical Scavenging Activity. The antioxidant activity was evaluated by scavenging the DPPH free radicals [19]. The procedure was as follows. A sample of known concentration $(0.5 \mathrm{~mL})$ (methanol for blank) was diluted with methanol $(3.5 \mathrm{~mL})$. DPPH solution $(0.5 \mathrm{~mL}, 1 \%$ in methanol) was added, and the solution was shaken and left to stand in the dark for $30 \mathrm{~min}$. Finally, the absorbance was measured at $517 \mathrm{~nm}$ using a microplate reader. The $\mathrm{IC}_{50}$ value was calculated based on the scavenging activity of the samples against $50 \%$ of DPPH radicals.

2.9. ABTS Radical Scavenging Activity. The ABTS radical scavenging activities were determined using the following procedure [20]. The ABTS solution was prepared by mixing ABTS $(7.4 \mathrm{mM})$ with potassium persulfate $(2.6 \mathrm{mM})$ and diluted with phosphate buffer saline $(\mathrm{pH} 7.4)$ until the absorbance of the ABTS solution was $0.70 \pm 0.01$ (a.u.) at
$734 \mathrm{~nm}$ on a UV 1800 spectrophotometer (Shimadzu, Japan). Thereafter, diluted ABTS solution $(950 \mu \mathrm{L})$ was allowed to react with the sample $(50 \mu \mathrm{L})$ for $7 \mathrm{~min}$ in the dark, and the absorbance was measured at $734 \mathrm{~nm}$. The ABTS radical scavenging activity was expressed as the ratio of the decrease in absorbance with and without the sample.

2.10. Cell Culture. RAW264.7 were cultured in DMEM (Gibco-BRL, Gaithersburg, MD, USA) with $10 \%$ heatinactivated FBS (Gibco-BRL), sodium pyruvate $(1 \mathrm{mmol} / \mathrm{L})$, penicillin $(50 \mathrm{IU} / \mathrm{mL})$, streptomycin $(50 \mu \mathrm{g} / \mathrm{mL}), \beta$-mercaptoethanol $\left(5 \times 10^{5} \mathrm{~mol} / \mathrm{L}\right)$, sodium pyruvate $(1 \mathrm{mM})$, nonessential amino acids, penicillin $\mathrm{G}(100 \mathrm{IU} / \mathrm{mL})$, and streptomycin $(100 \mu \mathrm{g} / \mathrm{mL})[21]$.

2.11. Cell Viability Experiment. Cell viability was assessed using a Cell Counting Kit-8 (CCK-8, Dojindo Laboratories, Kumamoto, Japan) according to the manufacturer's instructions. Briefly, CCK-8 $(10 \mu \mathrm{L})$ was added, and the cells were incubated for $60 \mathrm{~min}$ in a Corning Costar 48 well plate. The absorbance of the mixture was measured at $450 \mathrm{~nm}$. Cell viability was expressed as a percentage of the control (untreated) cells (100\% survival) [21].

2.12. Quantification of Cytokines. RAW 264.7 cells were treated in Corning Costar 48 well plates and stimulated with LPS $(1 \mu \mathrm{g} / \mathrm{mL})$ in the presence or absence of the extracts for $18 \mathrm{~h}$. The cell culture supernatants were analyzed to produce proinflammatory cytokine interleukin 6 (IL-6) and the antiinflammatory cytokine interleukin 10 (IL-10) using ELISA [21].

2.13. Measurement of NO Content. RAW 264.7 cells were seeded in a Corning Costar 48 well plate at a density of $10^{6}$ cells/well for $16 \mathrm{~h}$ before treatment. The cells were treated with the test agent for $60 \mathrm{~min}$ and activated with LPS $(1 \mu \mathrm{g} /$ $\mathrm{mL}$ ). The culture supernatants were obtained by centrifugation, and the NO concentrations were assessed by the Griess reaction using a $\mathrm{NaNO}_{2}$ standard curve at known concentrations [21].

2.14. Statistical Analyses. For statistical analysis, data obtained from independent experiments were expressed as mean \pm SD and were analyzed using the Student's $t$-test with ANOVA for multiple comparisons. Differences were considered significant at $p<0.05$.

\section{Results and Discussion}

3.1. Antioxidant Activities. The antioxidant capacities of three fractions ( $n$-hexane, ethyl acetate, and methanol) and the crude ethanol extract are listed in Table 1. Aside from the crude ethanol extract, the ethyl acetate fraction exhibited stronger antioxidant activity than the other fractions, exhibiting an $\mathrm{IC}_{50}$ value of 12.29 and $14.70 \mu \mathrm{g} / \mathrm{mL}$ in the DPPH and ABTS experiments, respectively. The antioxidant activity conforms with the high concentration of the total 
TABLE 1: The antioxidant activity, total polyphenols (TPs), and total flavonoids (TFs) content of crude ethanol extract and its derived fractions.

\begin{tabular}{|c|c|c|c|c|}
\hline \multirow{2}{*}{ Sample } & \multicolumn{2}{|c|}{$\mathrm{IC}_{50}(\mu \mathrm{g} / \mathrm{mL})$} & \multicolumn{2}{|c|}{ Content (mg/100 g dry sample) } \\
\hline & DPPH & $\mathrm{ABTS}^{\bullet+}$ & Polyphenols & Flavonoids \\
\hline Crude ethanol extract & $20.65 \pm 3.12^{*}$ & $13.93 \pm 2.18^{*}$ & $308.21 \pm 4.72^{c}$ & $97.8 \pm 10.25^{\mathrm{a}}$ \\
\hline n-Hexane fraction & $96.82 \pm 5.65^{*}$ & $71.82 \pm 5.39^{*}$ & $21.45 \pm 2.05^{\mathrm{a}}$ & $15.75 \pm 1.91^{\mathrm{C}}$ \\
\hline Ethyl acetate fraction & $12.69 \pm 2.35^{*}$ & $14.70 \pm 2.25^{*}$ & $259.12 \pm 1.42^{\mathrm{b}}$ & $56.07 \pm 2.23^{\mathrm{b}}$ \\
\hline Methanol fraction & $62.93 \pm 4.17^{*}$ & $49.34 \pm 3.62^{*}$ & $158.41 \pm 9.47^{\mathrm{d}}$ & $71.82 \pm 3.76^{\mathrm{C}}$ \\
\hline Vitamin C (positive control) & $3.66 \pm 0.28$ & - & & \\
\hline Trolox (positive control) & - & $2.90 \pm 0.03$ & & \\
\hline
\end{tabular}

Values represent the mean of three replicates $(n=3) \pm$ SD. Mean values followed by the different superscripts (a-d) in a column are significantly different $(p<0.05) .{ }^{*} p<0.05$ vs. positive control.

flavonoids (TFs) and polyphenols (TPs) of the ethyl acetate fraction $(56.07 \mathrm{mg} Q \mathrm{QE} / 100 \mathrm{~g}$ and $259.12 \mathrm{mg} \mathrm{GAE} / 100 \mathrm{~g}$ ). Free radicals and oxidants are known to enact a significant dual role as both toxic and beneficial reagents. The imbalance between free radicals and antioxidants (in favor of radicals) in living humans is called oxidative stress, and it causes degenerative diseases such as atherosclerosis, cancer, arthritis, diabetes, and aging [22-24]. Excessive generation of free radicals can trigger inflammation in type 2 diabetes mellitus [25]. In addition, the oxidative stress and inflammation can cause development of diabetic complications [26]. Therefore, antioxidants and anti-inflammatory compounds from plants may play a major role in preventing and treating these complications [27]. Many studies have showed that flavonoids and phenolics appeared to be the good antioxidants [28-31]. In addition to the antioxidant effects, they also exhibited anti-inflammatory activity $[32,33]$. The results of this study indicate that the crude ethanol extract and ethyl acetate fraction are potential sources of antioxidant compounds and Ruellia tuberosa may help prevent type 2 diabetes mellitus.

3.2. Effect of RTFs on Cell Viability. To examine the effect of Ruellia tuberosa fractions (RTFs) on inflammation in LPSinduced RAW 264.7 cells, ELISA and nitric oxide (NO) quantitation were performed with and without these fractions. The cytotoxic effect of the fractions and dexamethasone (Dex) on the cells were examined using the Cell Counting Kit-8 (CCK-8) assay. The cells were treated with various RTFs at different concentrations $(5-40 \mu \mathrm{g} / \mathrm{mL})$ or Dex $(100 \mathrm{nmol} / \mathrm{L})$ for the indicated times. The response of cell viability was represented by the cell viability index, in which the number of RAW264.7 cells cultured at $0 \mathrm{~h}$ was used as a reference point. Interestingly, the number of cells in all treatments indicated the proliferation of RAW264.7 cells after $18 \mathrm{~h}$ of exposure. Collectively, these results support the safety of all the fractions at the concentrations examined in RAW264.7 cells. Thus, the concentrations of RTFs in the $5-40 \mu \mathrm{g} / \mathrm{mL}$ range and Dex $(100 \mathrm{nmol} / \mathrm{L})$ were used for subsequent inflammatory assays (Figure 1).

3.3. Effect of RTFs on NO Production in LPS-Induced RAW 264.7 Cells. To assess the inflammatory ability of all fractions, LPS-induced inflation in macrophages was used as an in vitro model in this study. Treatment with LPS $(1 \mu \mathrm{g} / \mathrm{mL})$ alone induced a nonsignificant increase in the viability of RAW264.7 cells compared with noninduced RAW264.7 cells. Thus, LPS $(1 \mu \mathrm{g} / \mathrm{mL})$ was used to activate RAW264.7 cells in this study. The RAW 264.7 cells were treated with various concentrations $(5-40 \mu \mathrm{g} / \mathrm{mL})$ of RTFs, and inflammation was stimulated by LPS. The data indicated that NO generation in LPS-induced cells was significantly inhibited in a dose-dependent manner by the ethanol extract and the different fractions compared with LPS control cells $(p<0.05)$ (Figure 2). At a concentration of $40 \mu \mathrm{g} / \mathrm{mL}$, the ethyl acetate and methanol fractions decreased the NO production by $45.63 \%$ and $48.76 \%(p<0.05)$, respectively, compared with that of the LPS-treated cells. The positive control, Dex $(100 \mathrm{nmol} / \mathrm{L})$, decreased NO production by $51.83 \%(p<0.05)$. The results indicated that the two potentially effective extracts were the ethyl acetate and methanol fractions.

\subsection{Effects of RTFs on Cytokines IL-6 and IL-10 Production in} RAW 264.7 Cells. After $18 \mathrm{~h}$ of incubating with LPS $(1 \mu \mathrm{g} /$ $\mathrm{mL})$, RAW264.7 cells were cultured with various concentrations $(5,10,20,30$, and $40 \mu \mathrm{g} / \mathrm{mL})$ of RTFs for $45 \mathrm{~min}$ following the determination by the ELISA assay of proinflammatory cytokines (IL-6) and anti-inflammatory cytokines (IL-10) in macrophage cells according to the manufacturer's protocol. Both IL-6 and IL-10 were strongly expressed in LPS-activated RAW264.7 cells (Figures 3(a) and $3(b))$. The expression levels of IL- 6 and IL-10 in the native control RAW 264.7 cells were $0.03 \pm 0.0027 \mathrm{ng} / \mathrm{mL}$ and $0.078 \pm 0.0048 \mathrm{ng} / \mathrm{ml}$, respectively, which increased significantly to $1.20 \pm 0.0148 \mathrm{ng} / \mathrm{mL} \quad(p<0.05)$ and $0.97 \pm$ $0.0186 \mathrm{ng} / \mathrm{ml}(p<0.05)$ in the LPS-induced RAW264.7 cells, respectively. Interestingly, coculture with RTFs suppressed the expression of IL- 6 but did not increase IL-10 at all the tested concentrations. Many proinflammatory cytokines play an important role in the inflammatory response and have been shown to promote the risk of type 2 diabetes mellitus [34, 35]. Moreover, high content of anti-inflammatory and proinflammatory cytokines such as IL- 6 and IL10 is found in the plasma of type 2 diabetic patients $[36,37]$. The glucose homeostasis is regulated by IL6 cytokine [38]. The studies showed that patients with type 2 diabetes had a higher level of IL-6 compared with nondiabetic persons 


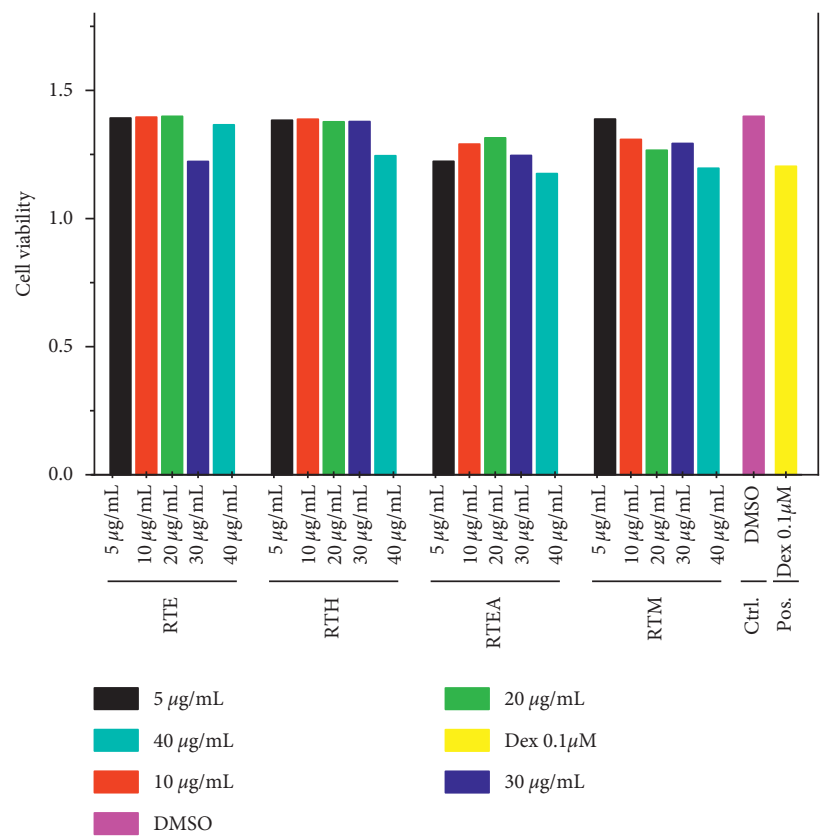

(a)

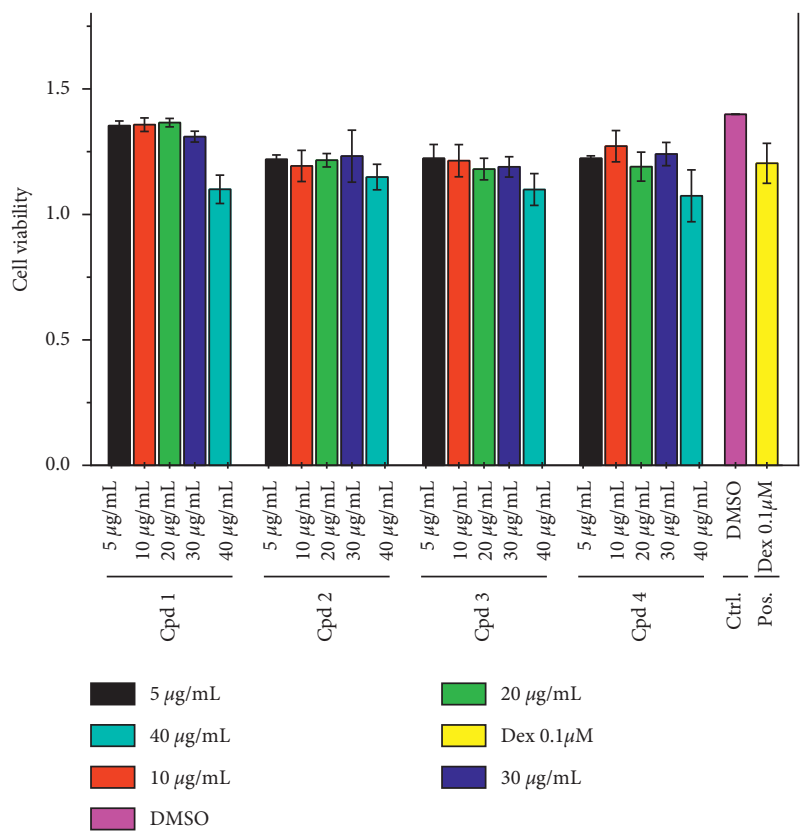

(b)

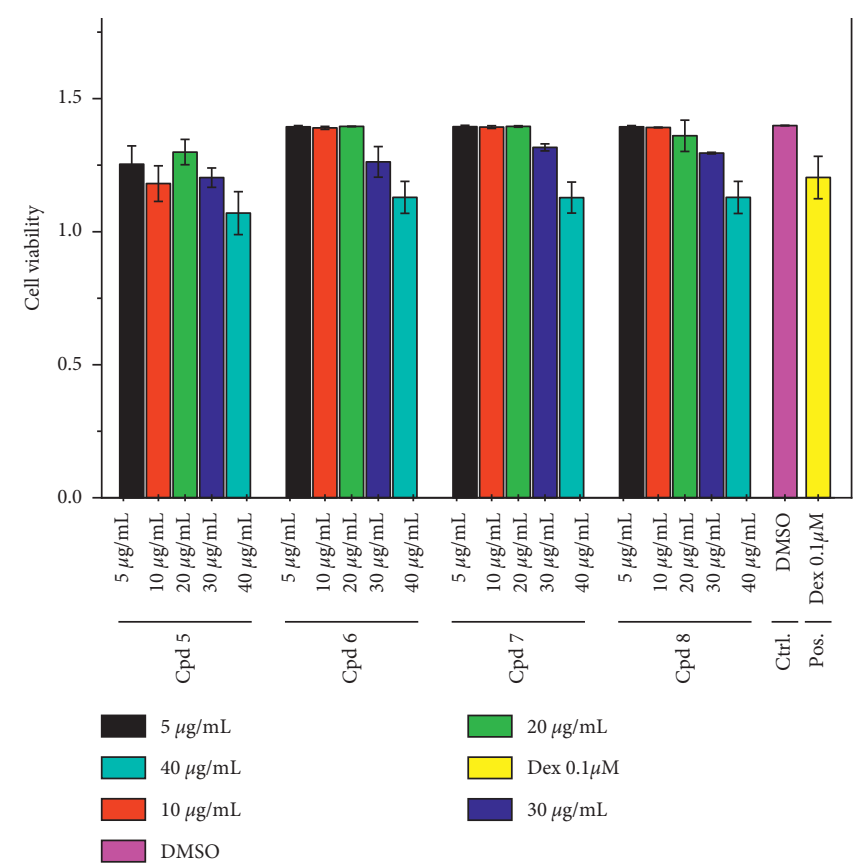

(c)

FIGURE 1: Effect of (a) extract, (b) compounds 1-4, and (c) compounds 5-8 on RAW 264.7 macrophage cell viability. Cells were incubated for $24 \mathrm{~h}$ with the indicated concentrations $(5,10,20,30$, and $40 \mu \mathrm{g} / \mathrm{mL})$. Data are expressed as mean \pm S.D. of three independent experiments. RTH: n-hexane fraction; RTEA: ethyl acetate fraction. RTM: methanol fraction; RTE: crude ethanol extract.

[39-41]. Meanwhile, IL-10 cytokine possesses both immunosuppressive and antiangiogenic function [42]. The level of IL-10 in people with impaired glucose tolerance or type 2 diabetes was lower than that in healthy control [43]. The present results show that RTFs possess a good anti-inflammatory activity, so they might efficiently prevent or slow down type 2 diabetes.
The level expression of IL- 6 was reduced to 5.99 and 5.72 times $(p<0.05)$ after a $45 \mathrm{~min}$ incubation with the methanol and ethyl acetate fractions at $30 \mu \mathrm{g} / \mathrm{mL}$ compared with the LPS-treated control cells, respectively. The inhibition of the IL-6 production by these two fractions (at a concentration of $30 \mu \mathrm{g} / \mathrm{mL}$ ) was equivalent to that of the positive control $(p<0.05)$. The hexane fraction and ethanol extract reduced 


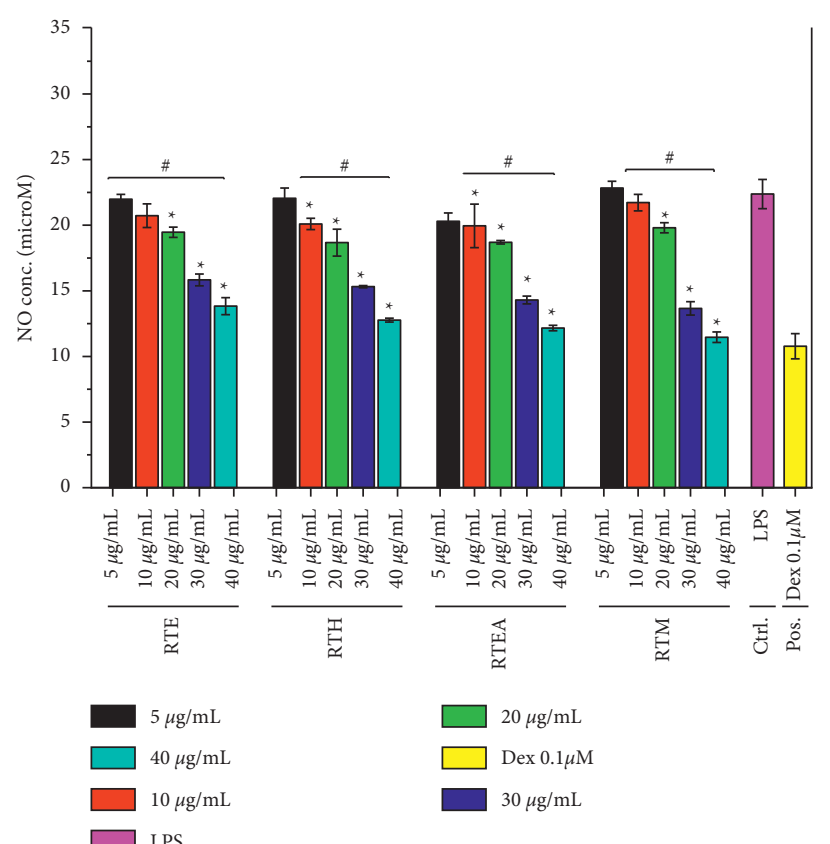

(a)

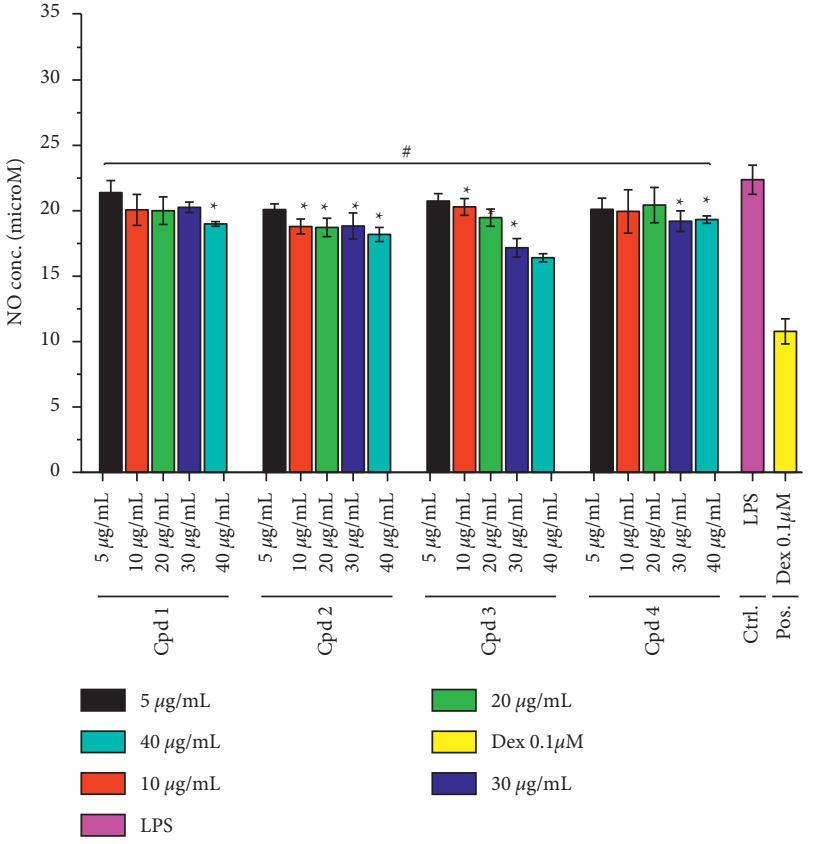

(b)

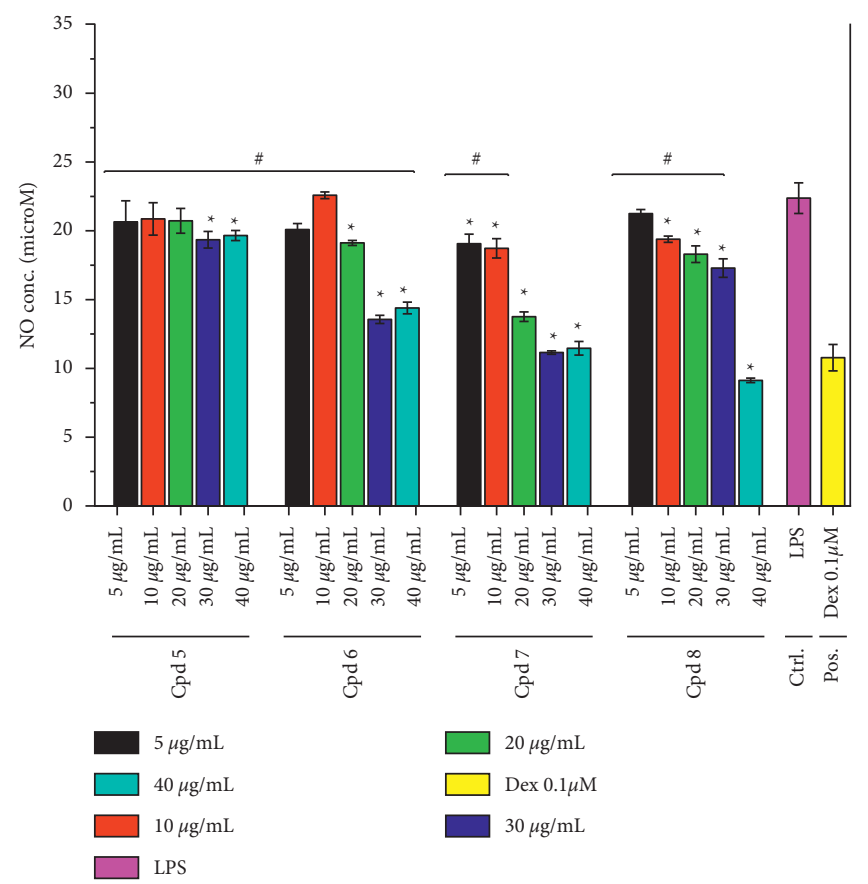

(c)

Figure 2: Effects of (a) extract and (b) compounds 1-4 and (c) 5-8 on the production of NO in LPS-induced RAW264.7 macrophages. Cells were pretreated for $2 \mathrm{~h}$ with the indicated concentrations $(5,10,20,30$, and $40 \mu \mathrm{g} / \mathrm{mL})$ and then stimulated with LPS $(1 \mu \mathrm{g} / \mathrm{mL})$ for another $24 \mathrm{~h}$. Data are expressed as mean \pm S.D. of three independent experiments. ${ }^{*} p<0.05$ versus the LPS group; ${ }^{*} p<0.05$ versus the positive group. RTH: (n)-hexane fraction; RTEA: ethyl acetate fraction. RTM: methanol fraction; RTE: crude ethanol extract.

the release of IL- 6 by three to four times compared with the LPS-activated cells. For IL-10, the RTFs significantly maintained the same level of IL-10 in the LPS-induced cells, although the concentration of RTFs increased from $5 \mu \mathrm{g} / \mathrm{mL}$ to $40 \mu \mathrm{g} / \mathrm{mL}$.
Collectively, the obtained data indicated that all the extracts and fractions can suppress the inflammation-associated expression of IL- 6 in the LPS-stimulated RAW 264.7 cells. However, the tendency of IL- 6 was upregulated with an increase in the RTF concentration $(>5 \mu \mathrm{g} / \mathrm{mL})$, 


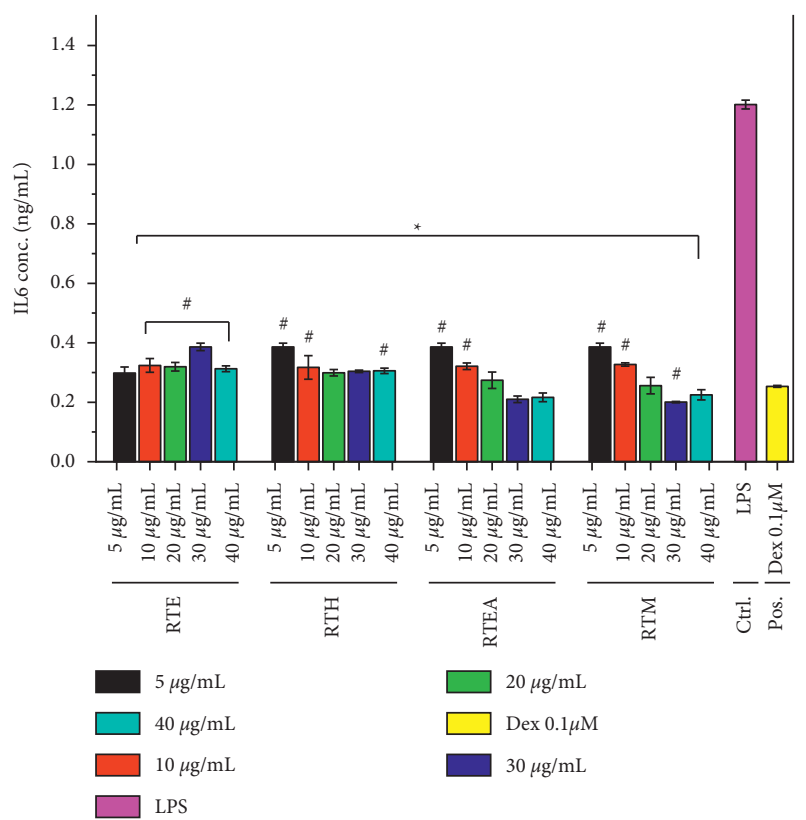

(a)

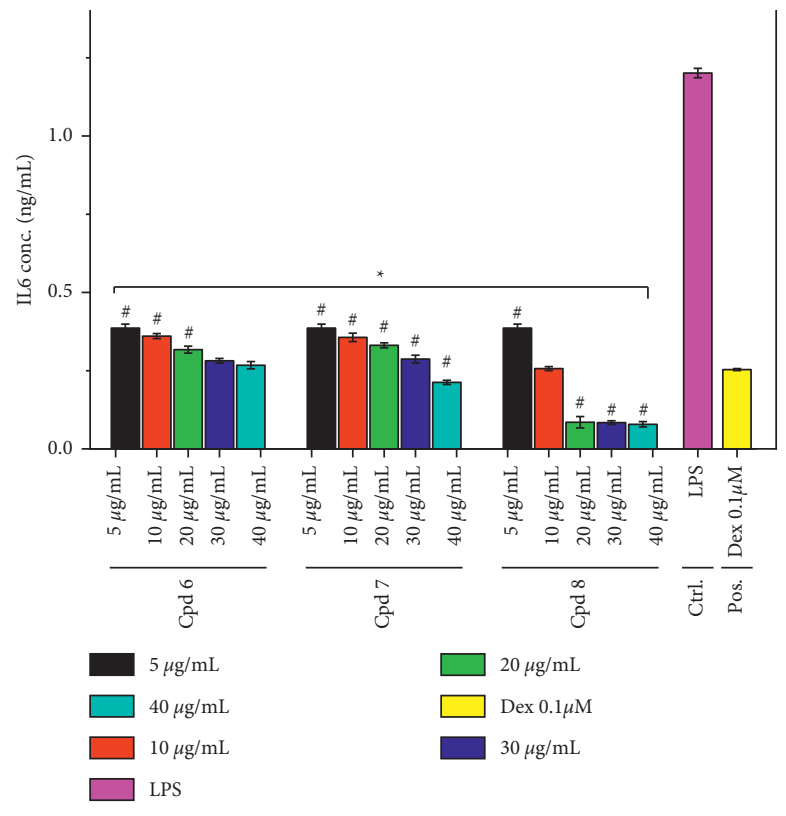

(c)

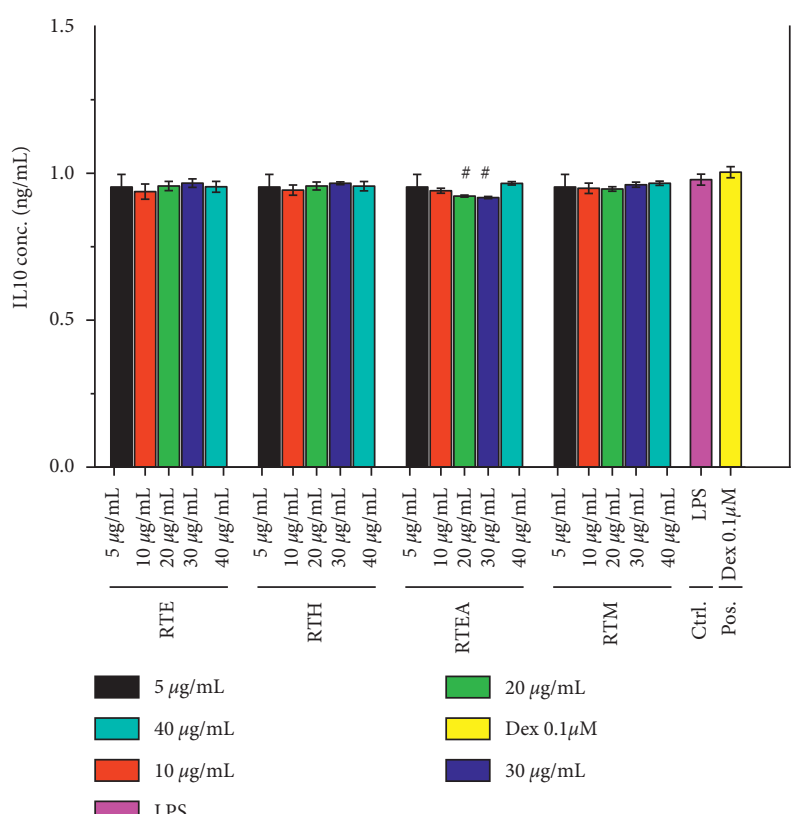

(b)

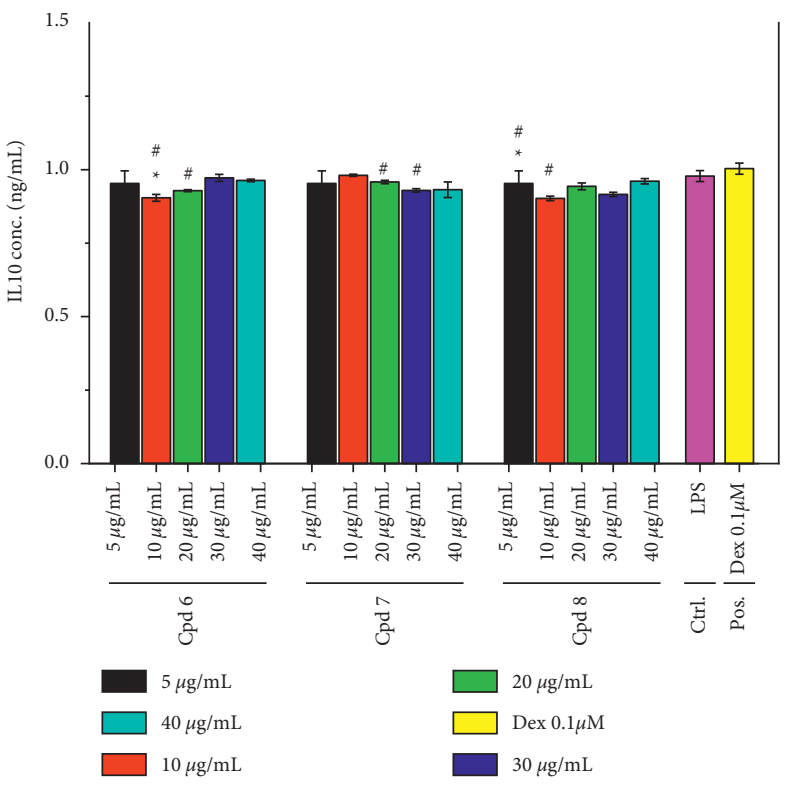

(d)

Figure 3: Effects on the secretion of IL-6 and IL-10 of the (a, b) extract and (c, d) compounds 6-8 in LPS-induced RAW 264.7 macrophages. Cells were pretreated for $2 \mathrm{~h}$ with indicated concentrations $(5,10,20,30$, and $40 \mu \mathrm{g} / \mathrm{mL})$ and then stimulated with LPS $(1 \mu \mathrm{g} / \mathrm{mL})$ for another $24 \mathrm{~h}$. Data are expressed as mean \pm S.D. of three independent experiments. ${ }^{*} p<0.05$ versus the LPS group; $\# p<0.05$ versus the positive group. RTH: (n)-hexane fraction; RTEA: ethyl acetate fraction; RTM: methanol fraction; RTE: crude ethanol extract.

whereas the IL-10 expression was independent of the RTF concentration. Specifically, the strongest inflammatory inhibition was observed in the methanol and ethyl acetate fractions. This suggests that there may have been active compounds present in the those fractions that exhibited counteracting effects [44-46].
3.5. Isolation of Potentially Anti-Inflammatory Compounds. The anti-inflammatory results indicated that ethyl acetate and methanol were the potential fractions that would contain the anti-inflammatory compounds. These fractions exhibited the highest activity in the downregulation of the proinflammatory cytokine IL-6 secretion and NO 

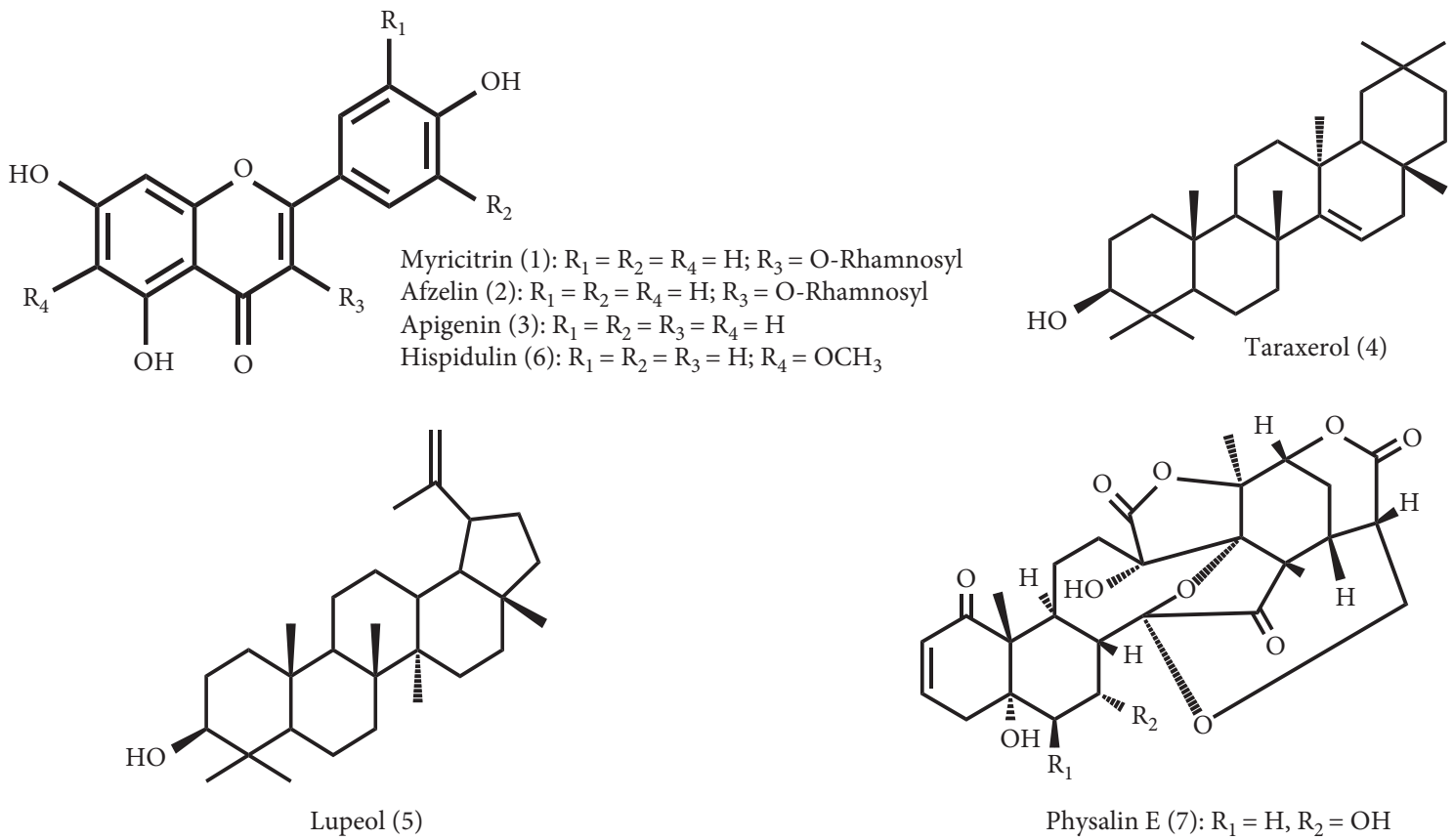

Physalin E (7): $\mathrm{R}_{1}=\mathrm{H}, \mathrm{R}_{2}=\mathrm{OH}$ Physalin D (8): $\mathrm{R}_{1}=\mathrm{OH}, \mathrm{R}_{2}=\mathrm{H}$

Figure 4: Chemical structure of isolated compounds. (a) Myricitrin (1): $\mathrm{R} 1=\mathrm{R}_{2}=\mathrm{R}_{4}=\mathrm{H} ; \mathrm{R}_{3}=\mathrm{O}-\mathrm{Rhamnosyl}$. Afzelin (2): $\mathrm{R}_{1}=\mathrm{R}_{2}=\mathrm{R}_{4}=\mathrm{H}$; $\mathrm{R}_{3}=\mathrm{O}$-Rhamnosyl. Apigenin (3): $\mathrm{R}_{1}=\mathrm{R}_{2}=\mathrm{R}_{3}=\mathrm{R}_{4}=\mathrm{H}$. Hispidulin (6): $\mathrm{R}_{1}=\mathrm{R}_{2}=\mathrm{R}_{3}=\mathrm{H} ; \mathrm{R}_{4}=\mathrm{OCH}_{3}$. (b) Taraxerol (4). (c) Lupol (5). (d) Physalin $\mathrm{E}$ (7) $\mathrm{R} 1=\mathrm{H}, \mathrm{R}_{2}=\mathrm{OH}$ Physalin E (8) $\mathrm{R} 1=\mathrm{OH}, \mathrm{R}_{2}=\mathrm{H}$.

production. Moreover, the ethyl acetate fraction contained the highest concentration of phenolic compounds and exhibited the strongest radical scavenging activities in the $\mathrm{DPPH}$ and ABTS assays compared with the other fractions. Therefore, the ethyl acetate fraction was chosen for further isolation and characterization of the bioactive compounds $[45,46]$. Eight compounds were isolated and identified after repeated chromatography of this fraction using normal and reversed phase silica gel and Sephadex LH-20 as adsorbents (Figure 4). These compounds were subsequently characterized as myricitrin (1) [47], afzelin (2) [48], apigenin (3) [49], taraxerol (4) [50], lupeol (5) [51], hispidulin (6) [52], physalin E (7) [53], and physalin D (8) [54], based on the detailed analysis (Table 2) of the NMR spectra (Figures S1-S16) and the published data. This is the first time that compounds 7 and $\mathbf{8}$ were isolated from the Ruellia genus. Compounds 1-6 are known to be present in R. tuberosa.

3.6. Effects of All Isolated Compounds (1-8) on NO Production in LPS-Induced RAW 264.7 Cells. The eight isolated compounds were further evaluated for their anti-inflammatory activity via NO production in the LPS-induced RAW 264.7 cells. Three compounds 6-8 exhibited a strong inhibitory effect on NO generation with the percentage inhibition ranging from $35.67 \%$ to $59.20 \%$ at a concentration of $40 \mu \mathrm{g} /$ $\mathrm{mL}$ (Figures 2(b) and 2(c)), compared with that of the LPS control cells $(p<0.05)$. Compound 3 exhibited moderate anti-inflammatory activity at all the evaluated concentrations $(p<0.05)$. Meanwhile, the four remaining compounds $(\mathbf{1}-\mathbf{3}, 5)$ exhibited weak activity for the inhibition of NO production.

3.7. Effects of Isolated Compounds on Cytokines IL6 and IL10 Production in RAW 264.7 Cells. Compounds 6-8 exhibited good NO inhibition activity, which required further investigation. The protein expression of IL- 6 and IL-10 increased significantly after stimulation with LPS $(p<0.05)$. Compared with the LPS-treated control cells, the positive control Dex $(1 \mu \mathrm{M})$ significantly suppressed the IL6 protein expression by a factor of $4.73(p<0.05)$, while physalin D (8) was the most effective compound, suppressing IL-6 secretion by a factor of 14 at a concentration of $20 \mu \mathrm{g} / \mathrm{mL}$ $(p<0.05)$. In addition, the level of expression of IL6 decreased by a factor of 3 and 8 (concentration dependent), by compounds 6 and 7, compared with the LPS control (Figure 3(c)). These compounds did not affect the secretion of IL10, and the level of the anti-inflammatory cytokine IL10 was maintained and independent of its concentration (Figure 3(d)). 


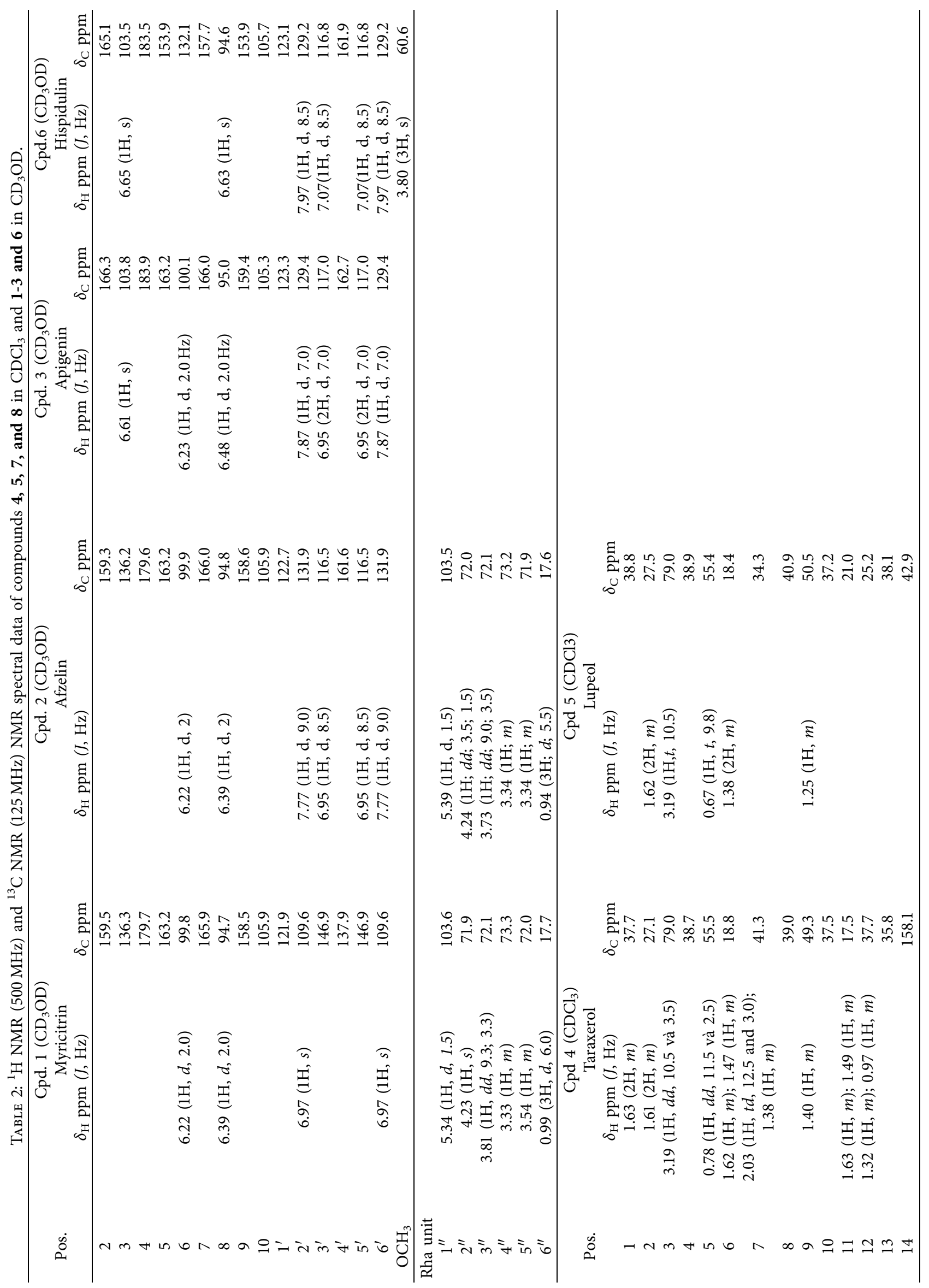




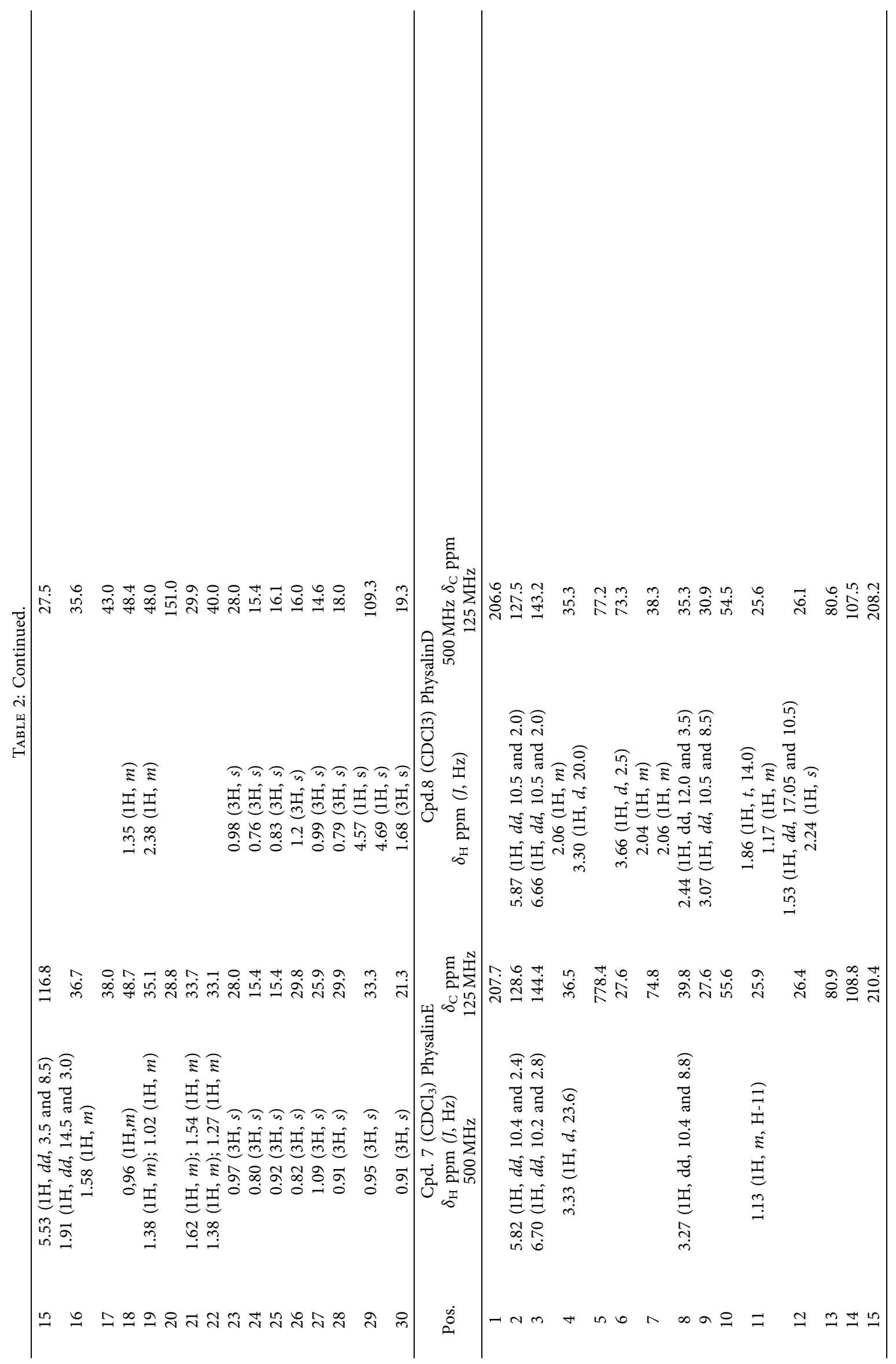




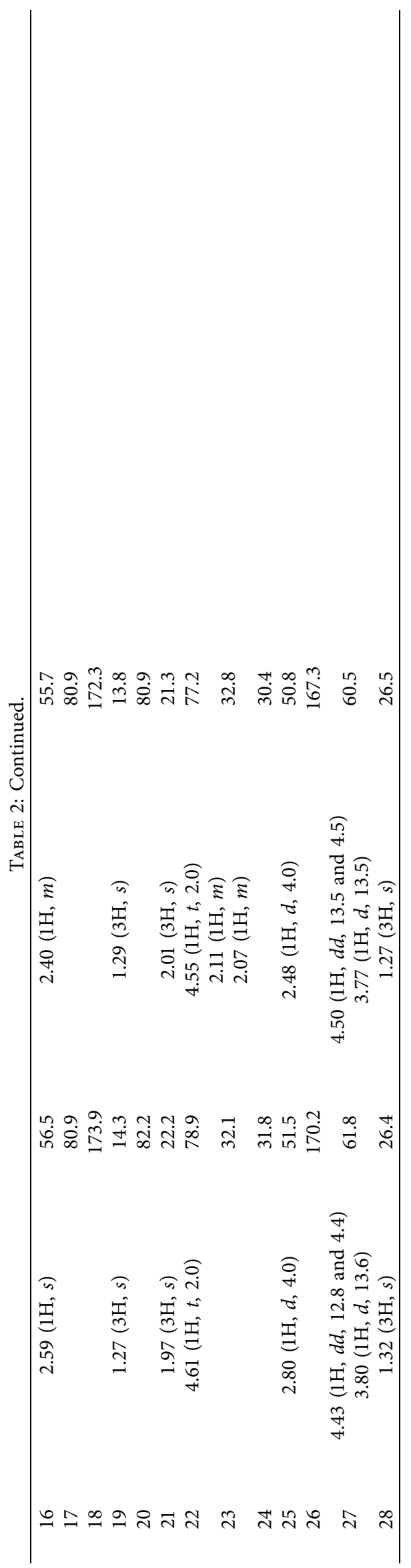




\section{Conclusions}

The present study was designed to evaluate the total flavonoids (TFs) and total polyphenols (TPs) combined with in vitro antioxidant and anti-inflammatory activities of the crude extract and fractions from aerial part of Ruellia tuberosa L. The ethyl acetate fraction (RTE) exhibited the most effective antioxidant activity against DPPH and ABTS radicals and also contained a high quantity of TFs and TPs. In the anti-inflammatory activity assay, the methanol and ethyl acetate fractions demonstrated the highest activity in the downregulation of the proinflammatory cytokine, IL6 secretion, and NO production at a concentration of $30 \mu \mathrm{g} / \mathrm{mL}$ in LPS-induced RAW 264.7 cells. Eight compounds were isolated and characterized from the RTE, of which three compounds 6-8 exhibited a strong inhibitory effect on NO generation. Physalin D (8) was the most effective compound when it inhibited IL-6 secretion by a factor of 14 at a concentration of $20 \mu \mathrm{g} / \mathrm{mL}$. Compounds 6 and 7 decreased the level of protein IL6 from 3 to 8 times compared with the LPS control group in a dose-dependent manner. Based on these data, physalin D (8), physalin E (7), and hispidulin (6) are potentially bioactive compounds for the treatment of inflammation symptoms in type 2 diabetes mellitus from herbal medicines based on Ruellia tuberosa $\mathrm{L}$.

\section{Abbreviations}

ABTS: 2,2-Azinobis-(3-ethylbenzothiazoline-6sulfonate)

DMEM: Dulbecco's modified Eagle's medium

DMSO: Dimethyl sulfoxide

DPPH: 2,2-Diphenyl-1-picryl-hydrazyl-hydrate

EDTA: Ethylenediaminetetraacetic acid

ELISA: Enzyme-linked immunosorbent assay

GAE: Gallic acid equivalent

$\mathrm{IC}_{50}$ : The half maximal inhibitory concentration

IL-10: Interleukin 10

IL-6: Interleukin 6

LPS: Lipopolysaccharide

ODS: Octadecylsilane

QE: Quercetin equivalent

RTE: Ruellia tuberosa L. extract

RTEA: Ruellia tuberosa ethyl acetate fraction

RTH: Ruellia tuberosa $n$-hexane fraction

RTM: Ruellia tuberosa methanol fraction

TLC: Thin layer chromatography.

\section{Data Availability}

The data used to support the findings of this study are included within the article.

\section{Conflicts of Interest}

The authors declare that there are no conflicts of interest regarding the publication of this article.

\section{Acknowledgments}

This research was funded by Vietnam National Foundation for Science and Technology Development (NAFOSTED) under grant no. 104.01-2017.54.

\section{Supplementary Materials}

Figure S1: ${ }^{1} \mathrm{H}$ NMR spectrum of compound 1. Figure $\mathrm{S} 2:{ }^{13} \mathrm{C}$ NMR spectrum of compound 1. Figure S3: ${ }^{1} \mathrm{H}$ NMR spectrum of compound 2. Figure S4: ${ }^{13} \mathrm{C}$ NMR spectrum of compound 2. Figure S5: ${ }^{1} \mathrm{H}$ NMR spectrum of compound 3. Figure S6: ${ }^{13} \mathrm{C}$ NMR spectrum of compound 3. Figure S7: ${ }^{1} \mathrm{H}$ NMR spectrum of compound 4. Figure S8: ${ }^{13} \mathrm{C}$ NMR spectrum of compound 4. Figure S9: ${ }^{1} \mathrm{H}$ NMR spectrum of compound 5. Figure S10: ${ }^{13} \mathrm{C}$ NMR spectrum of compound 5. Figure S11: ${ }^{1} \mathrm{H}$ NMR spectrum of compound 6. Figure S12: ${ }^{13} \mathrm{C}$ NMR spectrum of compound 6. Figure S13: ${ }^{1} \mathrm{H}$ NMR spectrum of compound 7. Figure S14: ${ }^{13} \mathrm{C}$ NMR spectrum of compound 7. Figure S15: ${ }^{1} \mathrm{H}$ NMR spectrum of compound 8. Figure S16: ${ }^{13} \mathrm{C}$ NMR spectrum of compound 8. (Supplementary Materials)

\section{References}

[1] N. Unwin and K. G. Alberti, "Chronic non-communicable diseases," Annals of Tropical Medicine and Parasitology, vol. 100, no. 5-6, pp. 455-464, 2006.

[2] V. Kothari, J. A. Galdo, and S. T. Mathews, "Hypoglycemic agents and potential anti-inflammatory activity," Journal of Inflammation Research, vol. 9, pp. 27-38, 2016.

[3] J. Montane, L. Cadavez, and A. Novials, "Stress and the inflammatory process: a major cause of pancreatic cell death in type 2 diabetes," Diabetes, Metabolic Syndrome and Obesity: Targets and Therapy, vol. 7, pp. 25-34, 2014.

[4] U. N. Tripathi and D. Chandra, "The plant extracts ofMomordica CharantiaandTrigonella foenum GraecumHave antioxidant and anti-hyperglycemic properties for cardiac tissue during diabetes mellitus," Oxidative Medicine and Cellular Longevity, vol. 2, no. 5, pp. 290-296, 2009.

[5] M. A. Babizhayev, I. A. Strokov, V. V. Nosikov et al., "The role of oxidative stress in diabetic neuropathy: generation of free radical species in the glycation reaction and gene polymorphisms encoding antioxidant enzymes to genetic susceptibility to diabetic neuropathy in population of type I diabetic patients," Cell Biochemistry and Biophysics, vol. 71, no. 3, pp. 1425-1443, 2015.

[6] B. Halliwell, "How to characterize an antioxidant: an update," Biochemical Society Symposia, vol. 61, pp. 73-101, 1995.

[7] N. T Pham Thi, N. An Pham, N. T. Tuan et al., "Research on phytochemical and alfa-glucosidase inhibitory activity of ethyl acetate fraction of Ruellia tuberosa," Vietnam Journal of Science and Technology, vol. 56, no. 4A, pp. 106-112, 2018.

[8] M. Rajan, V. K. KishorKumar, and P. S. SatheeshKumar, "Antidiabetic, antihyperlipidaemic and hepatoprotective activity of methanolic extract of Ruellia tuberosa Linn leaves in normal and alloxan induced diabetic rats," Journal of Chemical and Pharmaceutical Research, vol. 4, no. 6, pp. 2860-2868, 2012.

[9] D. Shahwara, S. Ullah, and M. Ahmad, "Hypoglycemic activity of Ruellia tuberosa Linn (Acanthaceae) in normal and 
alloxan-induced diabetic rabbits," Iranian Journal of Pharmaceutical Sciences, vol. 7, no. 2, pp. 107-115, 2011.

[10] K. Somia, S. U. Rehman, H. U. Shah et al., "In vitro enzyme inhibition activities of crude ethanolic extracts derived from medicinal plants of Pakistan," Natural Product Research, vol. 19, no. 6, pp. 567-571, 2005.

[11] C. F. Lin, Y. L. Huang, and L. Y. Cheng, "Bioactive flavonoids from Ruellia tuberosa," Journal of Chinese Medicine, vol. 17, no. 3, pp. 103-109, 2006.

[12] A. G. R. Nair and S. S. Subramanian, "Apigenin glycosides from Thunbergia fragrans and Ruellia tuberosa," Current Science, vol. 43, p. 480, 1974.

[13] H. Wagner, H. Danninger, M. A. Iyengar et al., "Synthese von Glucuroniden der Flavonoid-Reihe, III Isolierung von Apigenin-7- $\beta$ - D -glucuronid aus Ruellia tuberosa L. und seine Synthese," Chemische Berichte, vol. 104, no. 9, pp. 2681-2687, 1971.

[14] P. T. N. Trinh, N. T. T. Quynh, M. D. Tri et al., "New cerebroside and chondrocyte proliferation activity of Caryota mitis L," Natural Product Research, vol. 32, no. 22, pp. 2632-2638, 2018.

[15] P. T. N. Trinh, N. Q. Luan, M. D. Tri et al., "New naphthalene derivative from the leaves of Cassia grandis L," Natural Product Research, vol. 31, no. 15, pp. 1733-1738, 2017.

[16] P. T. N. Trinh, M. D. Tri, H. T. M. Nuong, and L. T. Dung, "Drybonioside, a new glucoside from the Drynaria bonii H. Christ Rhizomes," Natural Product Research, vol. 29, no. 2, pp. 137-140, 2015.

[17] Y. H. Lee, C. Choo, M. I. Watawana, N. Jayawardena, and V. Y. Waisundara, "An appraisal of eighteen commonly consumed edible plants as functional food based on their antioxidant and starch hydrolase inhibitory activities," Journal of the Science of Food and Agriculture, vol. 95, no. 14, pp. 2956-2964, 2015.

[18] G. Miliauskas, P. R. Venskutonis, and T. A. Van Beek, "Screening of radical scavenging activity of some medicinal and aromatic plant extracts," Food Chemistry, vol. 85, no. 2, pp. 231-237, 2004.

[19] T. C. Shekhar and G. Anju, "Antioxidant activity by DPPH radical scavenging method of Ageratum conyzoides Linn. leaves," American Journal of Ethnomedicine, vol. 1, no. 4, pp. 244-249, 2014.

[20] R. Re, N. Pellegrini, A. Proteggente, A. Pannala, M. Yang, and C. Rice-Evans, "Antioxidant activity applying an improved ABTS radical cation decolorization assay," Free Radical Biology \& Medicine, vol. 26, no. 9-10, pp. 1231-1237, 1999.

[21] S. Jung, M.-S. Lee, A.-J. Choi, C.-T. Kim, and Y. Kim, "Antiinflammatory effects of high hydrostatic pressure extract of mulberry (morus alba) fruit on LPS-stimulated RAW264.7 cells," Molecules, vol. 24, no. 7, p. 1425, 2019.

[22] L. A. Pham-Huy, H. He, and C. Pham-Huy, "Free radicals, antioxidants in disease and health," International Journal of Biomedical Sciences, vol. 4, no. 2, pp. 89-96, 2008.

[23] M. Valko, D. Leibfritz, J. Moncol, M. T. D. Cronin, M. Mazur, and J. Telser, "Free radicals and antioxidants in normal physiological functions and human disease," The International Journal of Biochemistry \& Cell Biology, vol. 39, no. 1, pp. 44-84, 2007.

[24] I. S. Young and J. Woodside, "Antioxidants in health and disease," Journal of Clinical Pathology, vol. 54, no. 3, pp. 176-186, 2001.

[25] M. S. H. Akash, K. Rehman, and S. Chen, "Role of inflammatory mechanisms in pathogenesis of type 2 diabetes mellitus," Journal of Cellular Biochemistry, vol. 114, no. 3, pp. 525-531, 2013.

[26] J. L. Rains and S. K. Jain, "Oxidative stress, insulin signaling, and diabetes," Free Radical Biology and Medicine, vol. 50, no. 5, pp. 567-575, 2011.

[27] N. K. Agrawal and S. Kant, "Targeting inflammation in diabetes: newer therapeutic options," World Journal of Diabetes, vol. 5, no. 5, pp. 697-710, 2014.

[28] A. Scalbert, C. Manach, C. Morand, C. Rémésy, and L. Jiménez, "Dietary polyphenols and the prevention of diseases," Critical Reviews in Food Science and Nutrition, vol. 45, no. 4, pp. 287-306, 2005.

[29] N. Deighton, R. Brennan, C. Finn, and H. V. Davies, "Antioxidant properties of domesticated and wildRubus species," Journal of the Science of Food and Agriculture, vol. 80, no. 9, pp. 1307-1313, 2000.

[30] P.-G. Pietta, "Flavonoids as antioxidants," Journal of Natural Products, vol. 63, no. 7, pp. 1035-1042, 2000.

[31] A. K. Gupta, S. Dhua, PP. Sahu, G. Abate, P. Mishra, and A. Mastinu, "Variation in phytochemical, antioxidant and volatile composition of pomelo fruit (citrus grandis (L.) osbeck) during seasonal growth and development," Plants, vol. 10, no. 9, p. 1941, 2021.

[32] A. S. Ravipati, L. Zhang, S. R. Koyyalamudi et al., "Antioxidant and anti-inflammatory activities of selected Chinese medicinal plants and their relation with antioxidant content," BMC Complementary and Alternative Medicine, vol. 12, no. 1, p. 173, 2012.

[33] G. Abate, L. Zhang, M. Pucci et al., "Phytochemical analysis and anti-inflammatory activity of different ethanolic phytoextracts of artemisia annua L," Biomolecules, vol. 11, no. 7, p. 975, 2021.

[34] F. B. Hu, J. B. Meigs, T. Y. Li, N. Rifai, and J. E. Manson, "Inflammatory markers and risk of developing type 2 diabetes in women," Diabetes, vol. 53, no. 3, pp. 693-700, 2004.

[35] M. I. Schmidt, B. B. Duncan, A. R. Sharrett et al., "Markers of inflammation and prediction of diabetes mellitus in adults (atherosclerosis risk in communities study): a cohort study," The Lancet, vol. 353, no. 9165, pp. 1649-1652, 1999.

[36] K. F. Rodrigues, N. T. Pietrani, A. A. Bosco, F. M. F. Campos, V. C. Sandrim, and K. B. Gomes, "IL-6, TNF- $\alpha$, and IL-10 levels/polymorphisms and their association with type 2 diabetes mellitus and obesity in Brazilian individuals," Archives of Endocrinology and Metabolism, vol. 61, no. 5, pp. 438-446, 2017.

[37] S. Gupta, A. Maratha, J. Siednienko et al., "Analysis of inflammatory cytokine and TLR expression levels in type 2 diabetes with complications," Scientific Reports, vol. 7, no. 1, p. 7633, 2017.

[38] M. Banerjee and M. Saxena, "Genetic polymorphisms of cytokine genes in type 2 diabetes mellitus," World Journal of Diabetes, vol. 5, no. 4, pp. 493-504, 2014.

[39] D. Hansen, P. Dendale, M. Beelen et al., "Plasma adipokine and inflammatory marker concentrations are altered in obese, as opposed to non-obese, type 2 diabetes patients," European Journal of Applied Physiology, vol. 109, no. 3, pp. 397-404, 2010.

[40] R. Goyal, A. F. Faizy, S. S. Siddiqui, and M. Singhai, "Evaluation of TNF- $\alpha$ and IL- 6 levels in obese and non-obese diabetics: pre- and postinsulin effects," North American Journal of Medical Sciences, vol. 4, no. 4, pp. 180-184, 2012.

[41] G. Daniele, R. Guardado Mendoza, D. Winnier et al., "The inflammatory status score including IL-6, TNF- $\alpha$, osteopontin, fractalkine, MCP-1 and adiponectin underlies whole- 
body insulin resistance and hyperglycemia in type 2 diabetes mellitus," Acta Diabetologica, vol. 51, no. 1, pp. 123-131, 2014.

[42] S. S. Iyer and G. Cheng, "Role of interleukin 10 transcriptional regulation in inflammation and autoimmune disease," Critical Reviews in Immunology, vol. 32, no. 1, pp. 23-63, 2012.

[43] M. Blüher, M. Fasshauer, A. Tönjes, J. Kratzsch, M. R. Schön, and R. Paschke, "Association of interleukin-6, C-reactive protein, interleukin-10 and adiponectin plasma concentrations with measures of obesity, insulin sensitivity and glucose metabolism," Experimental and Clinical Endocrinology o Diabetes, vol. 113, no. 9, pp. 534-537, 2015.

[44] S. H. Im, Z. Wang, S. S. Lim, O.-H. Lee, and I.-J. Kang, "Bioactivity-guided isolation and identification of anti-adipogenic compounds from Sanguisorba officinalis," Pharmaceutical Biology, vol. 55, no. 1, pp. 2057-2064, 2017.

[45] M. Ilhan, Z. Ali, I. A. Khan, H. Taştan, and E. Küpeli Akkol, "Bioactivity-guided isolation of flavonoids from Urtica dioica L. and their effect on endometriosis rat model," Journal of Ethnopharmacology, vol. 243, p. 112100, 2019.

[46] I. Yildiz, O. Sen, R. Erenler, I. Demirtas, and L. Behcet, "Bioactivity-guided isolation of flavonoids from Cynanchum acutum L. subsp. sibiricum (willd.) Rech. f. and investigation of their antiproliferative activity," Natural Product Research, vol. 31, no. 22, pp. 2629-2633, 2017.

[47] S.-Y. Mok and S. Lee, "Identification of flavonoids and flavonoid rhamnosides from Rhododendron mucronulatum for. albiflorum and their inhibitory activities against aldose reductase," Food Chemistry, vol. 136, no. 2, pp. 969-974, 2013.

[48] D. G. Lee, M. J. Ryu, S. Cho, H. S. Chung, and S. Lee, "Identification of afzelin and quercitrin from pinus koraiensis and their contents in genus pinus using HPLC/UV analysis," Natural Product Sciences, vol. 20, no. 3, pp. 206-210, 2014.

[49] P. Van Loo, A. De Bruyn, and M. Buděšínský, "Reinvestigation of the structural assignment of signals in the1H and13C NMR spectra of the flavone apigenin," Magnetic Resonance in Chemistry, vol. 24, no. 10, pp. 879-882, 1986.

[50] Y. C. Koay, K. C. Wong, H. Osman, I. Eldeen, and M. Z. Asmawi, "Chemical constituents and biological activities of Strobilanthes crispus L," Records of Natural Products, vol. 7, no. 1, pp. 59-64, 2013.

[51] A. Ben nejma, M. Besbes, V. Guérineau, D. Touboul, H. Ben jannet, and M. h. A. Hamza, "Isolation and structure elucidation of acetylcholinesterase lipophilic lupeol derivatives inhibitors from the latex of the Tunisian Periploca laevigata," Arabian Journal of Chemistry, vol. 10, no. 2, pp. S2767-S2772, 2017.

[52] T. Iwashina, K. Kamenosono, and T. Ueno, "Hispidulin and nepetin $4^{\prime}$-glucosides from Cirsium oligophyllum," Phytochemistry, vol. 51, no. 8, pp. 1109-1111, 1999.

[53] Y.-J. Yang, L. Yi, Q. Wang, B.-B. Xie, Y. Dong, and C.-W. Sha, "Anti-inflammatory effects of physalin E from Physalis angulata on lipopolysaccharide-stimulated RAW 264.7 cells through inhibition of NF- $\kappa \mathrm{B}$ pathway," Immunopharmacology and Immunotoxicology, vol. 39, no. 2, pp. 74-79, 2017.

[54] L. C. V. Cuong, T. T. H. Dat, N. X. Nhiem, N. T. Cuc, D. T. H. Yen, and H. L. T. Anh, "The anti-microbial activities of secosteroids isolated from Physalis angulata," Vietnam Journal of Chemistry, vol. 58, no. 3, pp. 321-326, 2020. 